\title{
Understanding materials challenges for rechargeable ion batteries with in situ transmission electron microscopy
}

\author{
Yifei Yuan ${ }^{1,2}$, Khalil Amine ${ }^{1}$, Jun Lu $\&$ Reza Shahbazian-Yassar ${ }^{2}$
}

An in-depth understanding of material behaviours under complex electrochemical environment is critical for the development of advanced materials for the next-generation rechargeable ion batteries. The dynamic conditions inside a working battery had not been intensively explored until the advent of various in situ characterization techniques. Real-time transmission electron microscopy of electrochemical reactions is one of the most significant breakthroughs poised to enable radical shift in our knowledge on how materials behave in the electrochemical environment. This review, therefore, summarizes the scientific discoveries enabled by in situ transmission electron microscopy, and specifically emphasizes the applicability of this technique to address the critical challenges in the rechargeable ion battery electrodes, electrolyte and their interfaces. New electrochemical systems such as lithium-oxygen, lithium-sulfur and sodium ion batteries are included, considering the rapidly increasing application of in situ transmission electron microscopy in these areas. A systematic comparison between lithium ion-based electrochemistry and sodium ion-based electrochemistry is also given in terms of their thermodynamic and kinetic differences. The effect of the electron beam on the validity of in situ observation is also covered. This review concludes by providing a renewed perspective for the future directions of in situ transmission electron microscopy in rechargeable ion batteries.

$\mathrm{n}$ spite of the widespread applications of rechargeable ion batteries, these devices still face various materials and interfacial challenges that exclude them from high power and high-performance applications. These problems are complicated because of the evolution of battery electrodes, electrolytes and solid electrolyte interphases (SEIs) during battery operation, which cannot be easily investigated under the required sealed working environment. Various methods such as X-ray and neutron scattering, Raman, cathodoluminescence and electrochemical impedance spectroscopy have been developed to characterize the material properties and behaviours in a battery. Among these techniques, transmission electron microscopy (TEM) stands out for high spatial/temporal resolution, superior sensitivity to

\footnotetext{
${ }^{1}$ Chemical Sciences and Engineering Division, Argonne National Laboratory, 9700 S Cass Avenue, Argonne, Illinois 60439, USA. ${ }^{2}$ Department of Mechanical and Industrial Engineering, University of Illinois at Chicago, Chicago, Illinois 60607, USA. Correspondence and requests for materials should be addressed to J.L. (email: junlu@anl.gov) or to R.S.-Y. (email: rsyassar@uic.edu)
} 
inhomogeneity and versatile capabilities for a systematic study of material phases, compositions and electronic structures. Therefore, real-time TEM techniques (in situ) are emerging as a powerful tool in revealing the underlying mechanisms responsible for the shortcomings of rechargeable ion batteries such as gradual capacity fading during cycling, poor power supply at low temperatures, thermal runaway and overcharge instability ${ }^{1}$.

Since the inception of in situ TEM techniques for battery research in 2010 (ref. 2), the electron microscopy community has been able to make exciting contributions to the fields that shed light on the understanding of material dynamics during electrochemical reactions. Therefore, it is an opportune time to review the most original contributions and discuss further opportunities in this area. This work differentiates itself from previous reviews on the application of in situ TEM in battery research $^{3-5}$ by focusing on the critical challenges in modern lithium ion batteries and beyond $\mathrm{Li}^{+}$systems, as well as on the differences between these systems. Figure la-e illustrates a working rechargeable ion battery where the most significant issues existing in the anode, cathode and liquid/solid electrolyte can be addressed by proper in situ TEM techniques. Examples of battery challenges are dendrite growth, cathode oxygen release, anode phase transformation, crystal expansion and interfacial delamination. Figure if categorizes the battery materials that have been studied using in situ TEM based on the specific electrochemical problem/issue they represent for the electrochemical systems based on both $\mathrm{Li}^{+}$and beyond $\mathrm{Li}^{+}$. The discussion is organized to highlight the most significant findings in charge storage mechanisms in the electrode, thermal stability and structural engineering of the electrode, as well as in liquid and solid electrolytes for both lithium ion systems and new battery chemistries. In addition, we discuss the side effect of the electron beam on the observed electrochemistry results, and to what extent the nanoscale discoveries by in situ TEM can be applied to real battery electrochemistry at bulk level. Finally, we have proposed some emerging research directions where in situ TEM can make significant contributions.

\section{In situ TEM for rechargeable ion batteries}

This review aims to address the in situ TEM-enabled scientific discoveries associated with the electrode, electrode/electrolyte interface of rechargeable ion batteries. Important considerations in the battery electrode, namely the charge storage dynamics and kinetics, the compositional and structural engineering and the thermal stability analysis are discussed in details. The electrode/electrolyte interface discussion mainly covers the topics of SEI and Li dendrite growth, and solid-state electrolytes. Battery systems beyond $\mathrm{Li}^{+}$are attracting more and more interest nowadays, where in situ TEM has shown great potential in analysing these systems. Related findings and achievements in the areas of rechargeable batteries with metallic lithium and rechargeable batteries with non-Li candidates are thus summarized. At last, the effect of the electron beam on in situ results and the data validity is discussed with emphasis on the open cell and the sealed liquid-cell designs.

Electrode. Development of advanced electrode materials such as $\mathrm{Mn}$-rich layered cathode and nanostructured $\mathrm{Si}$ anode is facing critical problems that demand in-depth understanding of electrochemical reactions. The scientific challenges include, but are not limited to, how cathodes experience thermal degradation with compromised battery safety, what is the charge storage mechanism for different materials, how $\mathrm{Li}$ dendrites evolve during $\mathrm{Li}(\mathrm{de})$ plating and why repetitive cycling leads to capacity fading. In situ TEM has been shown to be quite powerful in addressing these questions.

Charge storage dynamics and kinetics. Intercalation, alloying and conversion reactions are generally recognized as three mechanisms dominating $\mathrm{Li}^{+}$storage in battery electrodes ${ }^{6}$. Typical intercalation electrodes possess intrinsic one-, two- or three-dimensional openings to facilitate $\mathrm{Li}^{+}$transport without significant structural change ${ }^{6}$. The alloying mechanism proceeds by direct bonding between inserted $\mathrm{Li}^{+}$and the host element $\mathrm{A}$ (A for $\mathrm{Si}, \mathrm{Ge}, \mathrm{Sn}$, and so on) with formation of $\mathrm{Li}-\mathrm{A}$ alloys ${ }^{6}$. The conversion reaction happens when $\mathrm{Li}$ ions are inserted into nanosized binary compounds as denoted by MX ( $\mathrm{M}$ for transitional metals $\mathrm{Fe}, \mathrm{Co}, \mathrm{Cu}$, and so on, and $\mathrm{X}$ for $\mathrm{O}, \mathrm{S}, \mathrm{F}$, and so on), and results in reduction of $\mathrm{M}$ cations to $\mathrm{M}^{0}$ and formation of LiX (ref. 7). Generally, the three mechanisms direct charge storage of electrode materials so differently that the resultant electrode capacity, morphology and structure are sharply distinct. Extensive in situ TEM studies have been conducted to reveal the details of these charge storage mechanisms, which are discussed separately as following.

Ideally, intercalation electrodes should work without obvious structural degradation during ion insertion/extraction. Practically, however, localized structural instability has been reported mostly in the cathode side, leading to fast-capacity decay upon cycling. Therefore, it is necessary to understand the structural evolution details using in situ TEM possessing high spatial and temporal resolutions. In the case of $\mathrm{MnO}_{2}$ cathode featuring one-dimensional tunnelled structure, an asynchronous lattice expansion was found to be driven by sequential Jahn-Teller distortion of $\left[\mathrm{MnO}_{6}\right]$ octahedral (Fig. 2a) ${ }^{8}$. This asynchronous expansion degrades the original tetragonal symmetry and causes tunnel instability that leads to low practical capacity of rechargeable $\mathrm{Li} / \mathrm{MnO}_{2}$ batteries. The (dis)charge processes in $\mathrm{LiMn}_{2} \mathrm{O}_{4}$ cathode were found to exhibit a 'fringe' region featuring cubic-tetragonal transition (Fig. 2b), while no fracture or crack was found in $\mathrm{LiMn}_{2} \mathrm{O}_{4}$ nanowires ${ }^{9}$, suggesting possible structural modification and capacity retention via nanoscale engineering. Inhomogeneous (de)lithiation was revealed in $\mathrm{LiFePO}_{4}$ (LFP) nanoparticles using in situ liquid TEM (Fig. $2 \mathrm{c})^{10}$, which greatly supplements other in situ TEM reports showing either solid solution zones (Fig. 2d) $)^{11}$ or two-phase (LFP/FP) boundary (Fig. 2e $)^{12}$ in partially (de)lithiated LFP. These kinetic features could account for the poor cycling performance of LFP cathodes. The dynamic observation of structure degradation and phase boundary migration buried under electrode surfaces demonstrates the powerful capability of in situ TEM in detecting the localized reaction mechanisms that are otherwise difficult to study by other in situ or ex situ techniques. Inspired by such discoveries, the battery performance of these materials could be potentially improved by structural and compositional modification such as particle size reduction and trace elemental doping to reduce stress concentration and minimize structural degradation.

Among various alloying-based electrodes, silicon ( $\mathrm{Si}$ ) is of great interest because of its abundance in nature and high theoretical capacity of $4,200 \mathrm{mAhg}^{-1}$ via the reaction: $4.4 \mathrm{Li}^{+}+4.4+\mathrm{e}^{-}+\mathrm{Si}=\mathrm{Li}_{4.4} \mathrm{Si}$. However, Si undergoes detrimental pulverization and capacity fading during repetitive cycling. Accordingly, intensive in situ TEM work has been done to explore the failure mechanisms during the $\mathrm{Li}-\mathrm{Si}$ (de)alloying process (Fig. 3). To date, these discoveries include lithiationinduced amorphization ${ }^{13}$, size-sensitive fracturing ${ }^{14}$, self-limiting lithiation ${ }^{15}$, lithiation anisotropy ${ }^{16}$ and interfacial ledge-style lithiation $^{17}$. Besides Si, elemental anodes such as Sn (ref. 18), Ge (ref. 19) and Au (ref. 20) were also studied by in situ TEM, where distinct Li (de)alloying behaviours are discovered. These inspiring findings have greatly improved the development of 




Figure 1 | Various battery challenges and battery materials investigated by in situ TEM. (a-e) A working rechargeable ion battery (centre schematic) has many problems/challenges existing in the cathode, anode and liquid/solid electrolyte (inner circle), where each case is studied by a specific in situ TEM technique (outer circle). (a) A solid-state open cell exploring the structure failure (volume change, and so on) in anode. This design allows high spatial resolution imaging, but its point-contact geometry is different from the real battery environment flooded with liquid electrolytes. (b) A sealed liquid-cell investigating SEI and Li dendrites' evolution at the electrolyte/electrode interface. This design suffers from low spatial resolution, but it is a better match to the practical batteries. (c) An in situ heating stage analysing the thermal stability of metal oxide-based cathode, where surface degradation with $\mathrm{O}_{2}$ release and thermal runaway is the targeted problem. (d) An ionic liquid-based open cell studying the phase transition in metal oxide-based cathode, where detrimental phase transitions plague the overall performance. (e) A nanoscale thin-film battery studying solid-state electrolytes, where low ionic diffusivity and interface instability are the targeted problems. (f) Representative battery materials studied by in situ TEM 2,8-20,26-52,54-57,59-62,65-79,82,85,103-114. NCA, NMC, LFP, LMO and LCO stand for cathodes based on Ni-Co-Al-O, Ni-Mn-Co-O, LiFePO 4 , Li-Mn-O and Li-Co-O, respectively. LiPON, LLZO and LATSPO stand for solid-state electrolytes based on Li-P-O-N, Li-La-Zr-O and Li-Al-Ti-Si-P-O, respectively. For A-B expression, A represents the core component and $\mathrm{B}$ represents the shell or substrate component. CNF represents carbon nanofibres. 


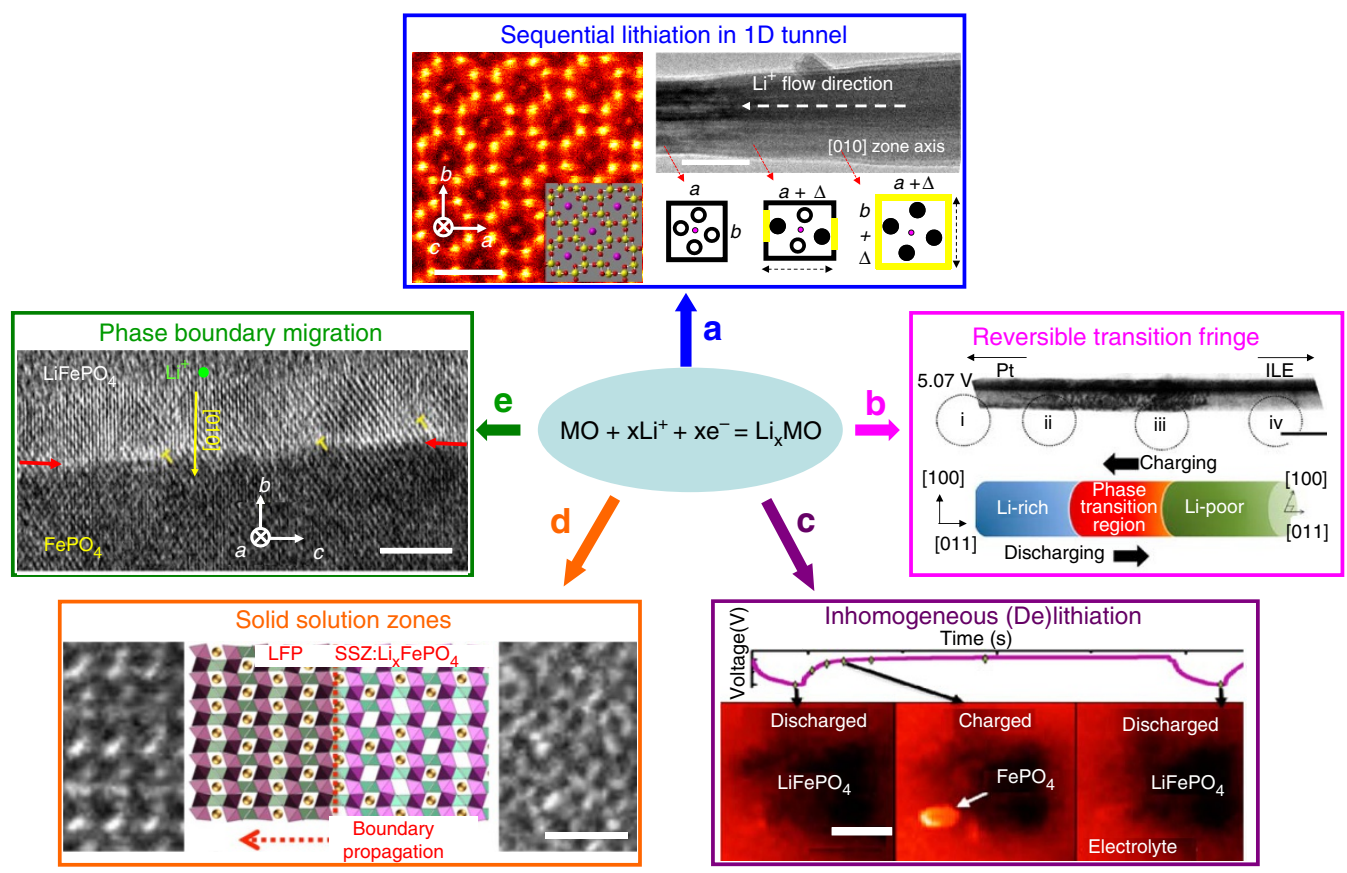

Figure 2 | Examples of intercalation mechanisms revealed by in situ TEM. (a) Sequential $\mathrm{Li}^{+}$filling inside $\alpha-\mathrm{MnO}_{2}$ tunnels leads to crystal expansion asymmetry. The left scale bar, $1 \mathrm{~nm}$, and the right bar, $50 \mathrm{~nm}$. Adapted from ref. 8 (Copyright 2015 American Chemical Society). (b) Reversible movement of a phase transition region (red) between Li-rich and Li-poor phases during cycling of a single $\mathrm{LiMn}_{2} \mathrm{O}_{4}$ nanowire-based battery was captured. Scale bar, $200 \mathrm{~nm}$. Adapted from ref. 9 (Copyright 2015 American Chemical Society). (c) Inhomogeneous (de)lithiation among LFP particles revealed by time-sequential energy-filtered TEM in an electrochemistry liquid cell. Scale bar, $200 \mathrm{~nm}$. Reproduced from ref. 10 (Copyright 2014 American Chemical Society). (d) The movement of a solid solution zone was captured dynamically during delithiation of a LFP crystal. Scale bar, $1 \mathrm{~nm}$. Adapted from ref. 11 (Copyright 2014 American Chemical Society). (e) The migration of a LFP/FP phase boundary was captured during lithiation with its migration direction identified as well. Scale bar, $5 \mathrm{~nm}$. Adapted from ref. 12 (Copyright 2013 WILEY-VCH Verlag GmbH \& Co. KGaA, Weinheim).

alloying electrodes, particularly Si-based anode. As such, their structural integrity and capacity retention are enhanced via surface and nanoscale engineering ${ }^{21-25}$.

Nanosized transitional metal oxides, sulfides and fluorides (MX) show reversible $\mathrm{Li}^{+}$storage through a conversion reaction to $\mathrm{M}^{0}$ and LiX (ref. 7). Despite the decent capacity of these materials, several prominent problems/unknowns exist, such as the origins for high reactivity of LiX, the intermediate steps involving multiphase reactions, the low coulombic efficiency (CE) and the large overpotential and fast-capacity fading upon cycling ${ }^{7}$. High-magnification in situ TEM has captured the reversible formation of extremely small metallic nanograins $M^{0}$ $(2-3 \mathrm{~nm})$ during the conversion of various MX phases ${ }^{26-29}$. Interestingly, these reduced $\mathrm{M}^{0}$ particles were found to be structurally connected with each other inside the LiX matrix, as illustrated in Fig. 4a, demonstrating the conductive Fe network after the conversion of $\mathrm{FeF}_{2}$ (ref. 29). The high surface area of the metallic nanograins and their network for fast electron conduction are critical to catalyse the reversible reaction involving LiX. Although the conversion reaction is thermodynamically favourable, nonequilibrium reaction kinetics were also revealed as evidenced by modified phase transition pathways and stepwise lithiation identified in nanosized $\mathrm{Fe}_{3} \mathrm{O}_{4}$ (Fig. $\left.4 \mathrm{~b}\right)^{30}$, $\mathrm{MoO}_{3}$ (ref. 31), $\mathrm{MnO}_{2}$ (ref. 8) and $\mathrm{RuO}_{2}$ (ref. 32). It is interesting to note that, even for materials containing the same metal cations (and anions), subtle differences in conversion kinetics exist. For example, while an intermediate insertion phase such as $\mathrm{Li}_{x} \mathrm{Fe}_{3} \mathrm{O}_{4}$ was detected prior to the conversion of nanosized $\mathrm{Fe}_{3} \mathrm{O}_{4}$ to $\mathrm{Fe}$ (ref. 30), the same was not observed for the conversion of nanosized $\mathrm{Fe}_{2} \mathrm{O}_{3}$ (ref. 33) or $\mathrm{FeF}_{2}$ (ref. 29) to Fe. Such differences in kinetics are possibly caused by the variation in ionic mobility of
$\mathrm{Li}^{+}$, cations and anions that are confined within specific lattice frames. These indicate that in-depth investigations by in situ TEM are necessary to further understand the differences in metal oxides, sulfides and fluorides. The low CE is caused by partial reversibility of the conversion reaction, where metallic $\mathrm{M}^{0}$ nanograins are not always oxidized back to the original oxidation state but a lower valence state, as exampled by the conversion path via $\mathrm{Cu}^{2+} \mathrm{O}-\mathrm{Cu}$ (discharge, $670 \mathrm{mAhg}^{-1}$ ) and $\mathrm{Cu}-\mathrm{Cu}^{1+}{ }_{2} \mathrm{O}$ (charge, $375 \mathrm{mAhg}^{-1}$ ) in $\mathrm{CuO}$ (Fig. 4c) ${ }^{34}$ and other transitional metal oxide (TMOs) such as $\mathrm{Fe}_{2} \mathrm{O}_{3}$ (ref. 33) and $\mathrm{Co}_{3} \mathrm{O}_{4}$ (ref. 26). The cycling capacity fading is largely attributed to the volume change during the repetitive (de)lithiation that results in host fracturing, as recorded in various materials such as $\mathrm{RuO}_{2}$ (Fig. 4d) ${ }^{32}$ and $\mathrm{Fe}_{2} \mathrm{O}_{3}$ (ref. 33). The highly localized structural and morphological features in nanoscale during the conversion reaction requires the application of in situ TEM rather than any other collective in situ techniques such X-ray diffraction, Raman or X-ray photoemission spectroscopy. These in situ TEM findings strongly suggest the necessity of applying structural engineering and surface modification to improve the cycling stability of the TMO-based electrodes.

Compositional/structural engineering. Novel concepts have been implemented to improve the energy-storage performance of electrode materials via compositional design and structural engineering ${ }^{35}$. Although they are demonstrated to be effective, the underlying mechanisms improving the overall performance are poorly understood. Real-time TEM has been employed to study the working mechanisms of these concepts.

Silicon composited with carbon has been extensively studied to boost the electrical conductivity and mechanical flexibility of silicon anode. The spatial correlation between $\mathrm{Si}$ and carbon 


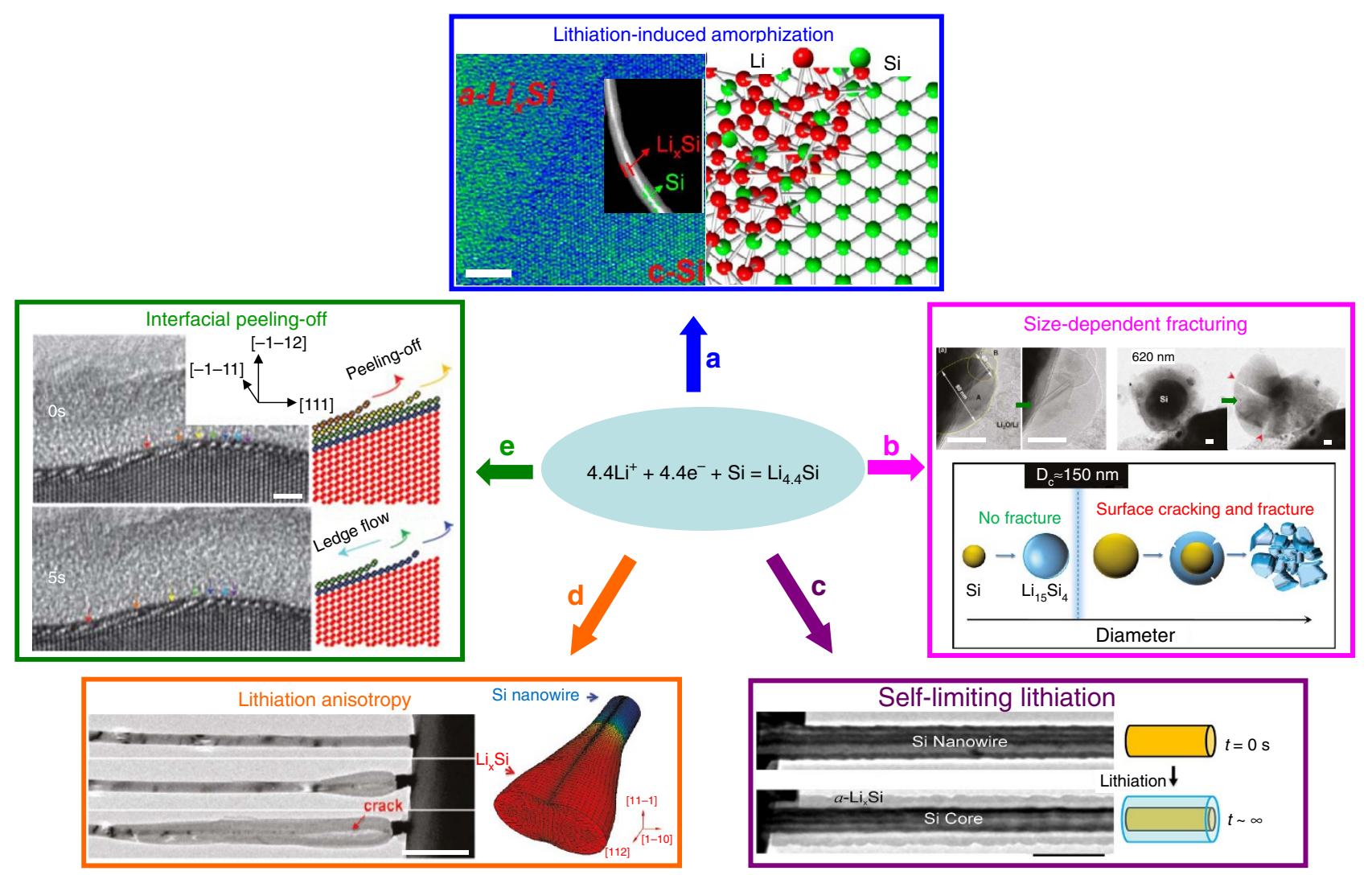

Figure 3 | Alloying reactions between Li and Si studied by in situ TEM. (a) Evolution of the two-phase microstructure (Si-Li $\mathrm{L}_{x} \mathrm{Si}$ core-shell) in one Si nanowire during lithiation. Scale bar, $5 \mathrm{~nm}$. Adapted from ref. 13 (Copyright 2013 American Chemical Society). (b) Size-dependent fracturing of lithiated c-Si. Scale bars, $50 \mathrm{~nm}$. Adapted from ref. 14 (Copyright 2012 American Chemical Society). (c) Self-limiting lithiation in single c-Si nanowire. Scale bar, $250 \mathrm{~nm}$. Reproduced from ref. 15 (Copyright 2013 American Chemical Society). (d) Anisotropic expansion of lithiated c-Si nanowire leading to dumbbell morphology. Scale bar, $1 \mu \mathrm{m}$. Adapted from ref. 16 (Copyright 2011 American Chemical Society). (e) The lithiation of $c-S i$ featuring lateral movement of ledges on the close-packed $\{111\}$ atomic planes. Scale bar, $2 \mathrm{~nm}$. Adapted from ref. 17 (Copyright 2012 Nature Publishing Group).

matrix and how various $\mathrm{Si}-\mathrm{C}$ architectures (surface-attached $\mathrm{Si}$, root-in-carbon $\mathrm{Si}$ ) affect the (de)lithiation behaviours were well explored (Fig. 5a) ${ }^{36}$. Additional configurations have been further explored such as $\mathrm{Si}$-carbon nanofibres ${ }^{37}$, Si-graphene ${ }^{38}$ and $\mathrm{Si}-\mathrm{C}$ yolk-shell composites (Fig. $5 \mathrm{~b})^{39}$, as well as other composite systems beyond $\mathrm{Si}-\mathrm{C}\left(\mathrm{CoS}_{2}\right.$-graphene ${ }^{27}, \mathrm{NiO}-$ graphene ${ }^{35}$ and Si-Sn (ref. 40)). Generally, two mechanisms were revealed by these studies, that is, the composites not only buffer the large volumetric variation of the loaded active materials and maintain stable SEI coatings on the surface, but also provide long-lasting $\mathrm{e}^{-} / \mathrm{Li}^{+}$pathways during repetitive cycling. In addition, a novel bandgap engineering theory was demonstrated using $\mathrm{Ge}-\mathrm{Si}$ composite (Fig. $5 c)^{4 \mathrm{P}}$, where a super thin $(1-5 \mathrm{~nm})$ Si coating on Ge surface efficiently changes the lithiation kinetics of Ge core. Next-generation batteries could potentially benefit from this idea by utilizing composite electrodes possessing less weight but better performance.

Crystal defects are conventionally expected to degrade battery performance, while in situ TEM has revealed positive roles of defects in enhancing battery reaction kinetics. For example, lithiation featuring stress-driven dislocation plasticity ${ }^{2}$ and twin boundary-assisted $\mathrm{Li}^{+}$transport (Fig. $5 \mathrm{~d}$ ) ${ }^{42}$ were both discovered in crystalline $\mathrm{SnO}_{2}$ nanowires. Future battery work is expected to greatly benefit from these fundamental studies, assuming that the crystalline defects (dislocations, twins, stacking faults) could be reasonably generated and controlled during material synthesis.

Thermal stability analysis. With the increasing demand for densely packed lithium ion batteries for high-energy density applications, safety has become one of the major concerns. Localized thermal failure could result in chain reactions for largescale thermal release and even explosion particularly in Co $(\mathrm{Ni}, \mathrm{Mn})$-rich oxides at their charged states. Understanding the mechanisms of thermal failure is thus the prerequisite for effective improvement of battery safety.

With an in situ heating stage in TEM, the thermal decomposition of $\mathrm{Li}_{x} \mathrm{Ni}_{0.8} \mathrm{Co}_{0.15} \mathrm{Al}_{0.05} \mathrm{O}_{2}$ particles up to $450^{\circ} \mathrm{C}$ was systematically studied and a layer to rock salt phase transition as well as surface porosity evolution associated with $\mathrm{O}$ release are dynamically recorded ${ }^{43}$. The origin of $\mathrm{O}$ release was further confirmed to be related to the reduction of $\mathrm{Ni}$, which turns out to be less stable than other elements such as Mn and Co (ref. 44), indicating that the improved energy density of Ni-rich cathode materials can be compromised by its thermal instability. Real-time observation of $\mathrm{O}$ loss behaviours was also reported for $\mathrm{LiCoO}_{2}$, the well-known commercialized cathode material for lithium ion battery, where the $\mathrm{O}$ evolution shows facet-dependent feature and is correlated with local-phase transition (layer-spinel-rock salt) upon heating ${ }^{45}$. Future work should focus on engineering the electrode compositions and particle facets to reach a balance between synthesis cost, energy density and thermal stability.

Electrochemistry interface. SEI and Li dendrite growth. Direct observation of the evolution of SEI and $\mathrm{Li}$ (de)plating on electrode/electrolyte interface with high spatial resolution is the prerequisite for understanding and improving interface-limited 

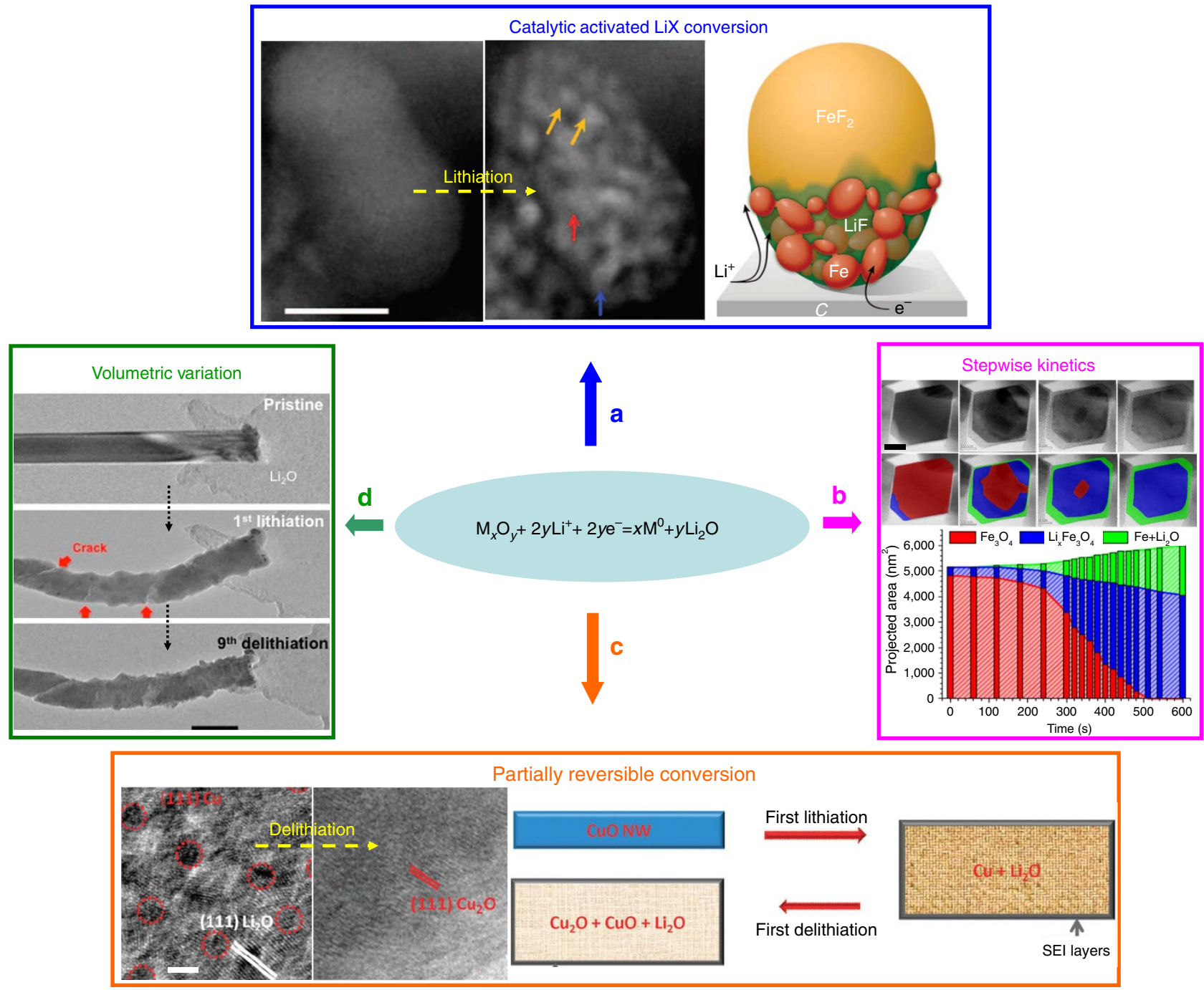

Figure 4 | Mechanisms of conversion-based electrode explored by in situ TEM. (a) high resolution transmission electron microscopy (HRTEM) images and schematic showing the interconnected metal nanograins of several nanometres that improve the reactivity of LiX. Scale bar, $10 \mathrm{~nm}$. Adapted from ref. 29 (Copyright 2012 Nature Publishing Group). (b) The identification of intermediate (intercalated) phases during the stepwise lithiation of Fe $\mathrm{O}_{4}$ ( $(\mathrm{ref}$. 30). Scale bar, $20 \mathrm{~nm}$. (c) The low coulombic efficiency caused by the partially reversible conversion reaction between $\mathrm{Cu}^{0}$ and $\mathrm{Cu}^{2+}$. Scale bar, $2 \mathrm{~nm}$. Adapted from ref. 34 (Copyright 2012 Royal Society of Chemistry). (d) Fracture formation in a $\mathrm{RuO}_{2}$ nanowire caused by volumetric variation during repetitive (de)lithiation. Scale bar, $100 \mathrm{~nm}$. Adapted from ref. 32 (Copyright 2013 American Chemical Society).

electrochemistry in batteries. Using in situ TEM, the substratesensitive Li plating behaviour (Fig. $6 \mathrm{a})^{46}$ and the tunable Li plating and SEI stability via nanoscale interfacial engineering ${ }^{47}$ were both discovered, which could potentially guide the electrode design with stabilized metallic $\mathrm{Li}$ anode for better cycling durability.

Since the actual environment for SEI evolution and $\mathrm{Li}$ (de)plating typically contains liquid-based electrolytes, a sealed liquid cell has been increasingly utilized to mimic the authentic battery reaction environment ${ }^{0,48}$. Li dendrite growth and SEI formation/decomposition in a $\mathrm{LiPF}_{6} /$ ethylene carbonate (EC)/ diethyl carbonate (DEC) electrolyte was dynamically recorded at nanoscale resolution (Fig. $6 \mathrm{~b})^{49}$, where the kinetics of Li dendrite growth and dissolution are explored to explain the formation of 'dead' Li during cycling. The overpotential-dependent Li protrusion (root growth versus tip growth) was recently reported, where root-grown whiskers were seen to be highly unstable upon delithiation ${ }^{50}$. SEI formation kinetics were also found to be limited by electron transport as extensively confirmed ${ }^{48,51}$. In a $\mathrm{LiPF}_{6} / \mathrm{EC} / \mathrm{DMC}$ liquid electrolyte, surprisingly, SEI formation is not uniform but in the shape of 'dendrites' similar to Li dendrites, and its growth is followed by $\mathrm{Li}$ plating ${ }^{52}$, implying the critical effect of electrolyte composition and electrode decomposition on $\mathrm{Li}$ plating. These in situ observations could help researchers to understand the kinetics of Li deposition and SEI growth and further to circumvent the related problems and battery failure.

Solid-state electrolyte. Compared to the conventional flammable liquid electrolyte in lithium ion batteries, solid-state electrolyte (SSE) is safe, nonflammable and compatible with metallic $\mathrm{Li}$, and even allows more flexible configurations such as thin film and miniature batteries ${ }^{53}$. Currently, however, there are several critical issues not well understood, such as interfacial electric potential distribution, nanoscale (miniature battery) electrochemistry and $\mathrm{Li}^{+}$transport property around the interface region. In situ TEM with analytical capability has been intensively applied to dynamically track interfacial $\mathrm{Li}^{+}$ diffusion/migration kinetics, providing in-depth understanding of the ionic transport mechanisms. 

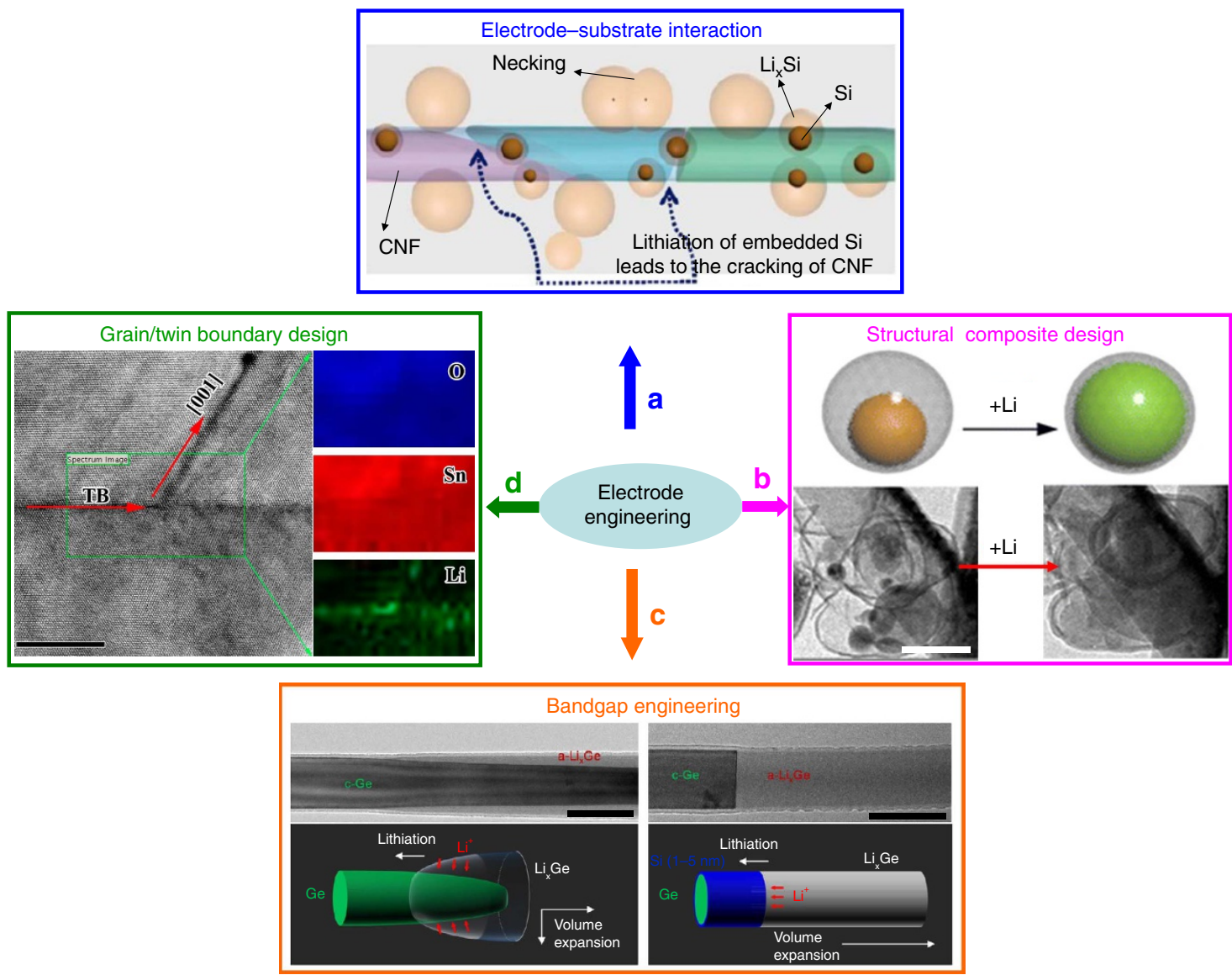

Figure 5 | Mechanisms of compositional/structural engineering of electrode materials explored by in situ TEM. (a) Lithiation characteristics of Si particles attached to and embedded in the CNF. Adapted from ref. 36 (Copyright 2012 American Chemical Society). (b) Core-shell composite showing a free expanding Si core with stable carbon shell and SEl. Scale bar, $200 \mathrm{~nm}$. Adapted from ref. 39 (Copyright 2012 American Chemical Society). (c) Lithiation kinetics in Ge core efficiently tuned by bandgap engineering using an extremely thin Si coating. Scale bars, $100 \mathrm{~nm}$. Adapted from ref. 41 (Copyright 2013 American Chemical Society). (d) Twin boundary-assisted lithiation in $\mathrm{SnO}_{2}$. Scale bar, $10 \mathrm{~nm}$. Reproduced from ref. 42 (Copyright 2015 American Chemical Society).

So far, two representative designs for the miniature solid-state batteries are proposed for in situ TEM study, that is, the single nanowire-based battery (Fig. 6c) and the thin-film battery (Fig. 6d). The former design enabled the discovery of size-sensitive selfdischarge due to a short circuit caused by space-charge-limited electronic conduction ${ }^{54}$, thus providing useful metric guidelines for future miniature three-dimensional battery design. Nanoscale spectroscopic characterization across solid electrolyte/electrode interfaces $\left(\mathrm{LiCoO}_{2} / \mathrm{LiPON}\right.$ and c-LLZO/Li) captured the existence of structurally disordered domains, unit cell-level phase transition and subsequent electronic structure change of transitional metals in the formed interphases (Fig. 6d) ${ }^{55,56}$. Within the similar thin-film battery design, the dynamic two-dimensional (2D) potential distribution caused by movement of $\mathrm{Li}^{+}$near the cathode/SSE interface was quantified by in situ holography ${ }^{57}$. These in situ discoveries explain the commonly observed interfacial impedance in solid-state batteries. They also reveal the dynamic formation of electrode/SSE interfaces with factors affecting the interfacial stability and dimension, which thus provides a new perspective for designing Li/SSE/cathode assembly for next-generation batteries.

Beyond lithium ion battery. Rechargeable batteries with metallic lithium. Current lithium ion batteries can hardly reach the high-energy density or longevity requirement to power electric vehicles with comparable performance to that of vehicles with internal combustion engines. Therefore, new electrochemical couples such as $\mathrm{Li}-\mathrm{O}_{2}$ and $\mathrm{Li}-\mathrm{S}$ are being targetedbecause of the much higher energy density ${ }^{58}$. Up to now, however, neither of them is commercialized due to practical challenges such as the large overpotential in the oxygen reduction reaction (ORR) and oxygen evolution reaction (OER), and the insulating property of $\mathrm{Li}_{2} \mathrm{~S}$ and S (ref. 58). Until now, there are only a few in situ TEM publications focusing on the dynamic study of Li-S and $\mathrm{Li}-\mathrm{O}_{2}$ electrochemistry.

The origin of the large charge overpotential in $\mathrm{Li}-\mathrm{O}_{2}$ batteries has been ascribed to the $\mathrm{e}^{-}$transport-limited charge kinetics based on in situ observation of $\mathrm{Li}_{2} \mathrm{O}_{2}$ decomposition using an open cell configuration ${ }^{59}$. Similar charge characteristics were also observed later from an organic liquid electrolyte, while the discharge process is surprisingly limited by $\mathrm{Li}^{+}$diffusion, resulting in large overpotential during discharge as well ${ }^{60}$. These in situ reports demonstrate the importance of designing conductive porous cathode materials with ability to confine the dissolution of $\mathrm{Li}_{2} \mathrm{O}_{2}$ into the electrolytes as well as to maintain a good conductive path. For Li-S electrochemistry, the existence of $\mathrm{S}_{8} / \mathrm{Li}_{2} \mathrm{~S}$ interface during discharge was captured in real time ${ }^{61}$, which was believed to prevent further $\mathrm{Li}^{+}$diffusion into the bulk sulfur due to the insulating character of $\mathrm{Li}_{2} \mathrm{~S}$. Interestingly, a different theory regarding the observed flat $\mathrm{Li}_{2} \mathrm{~S} / \mathrm{S}$ interface was developed later to infer the electrically conductive property of such a $\mathrm{Li}_{2} \mathrm{~S} / \mathrm{S}_{8}$ interface ${ }^{62}$, which could thus encourage the 

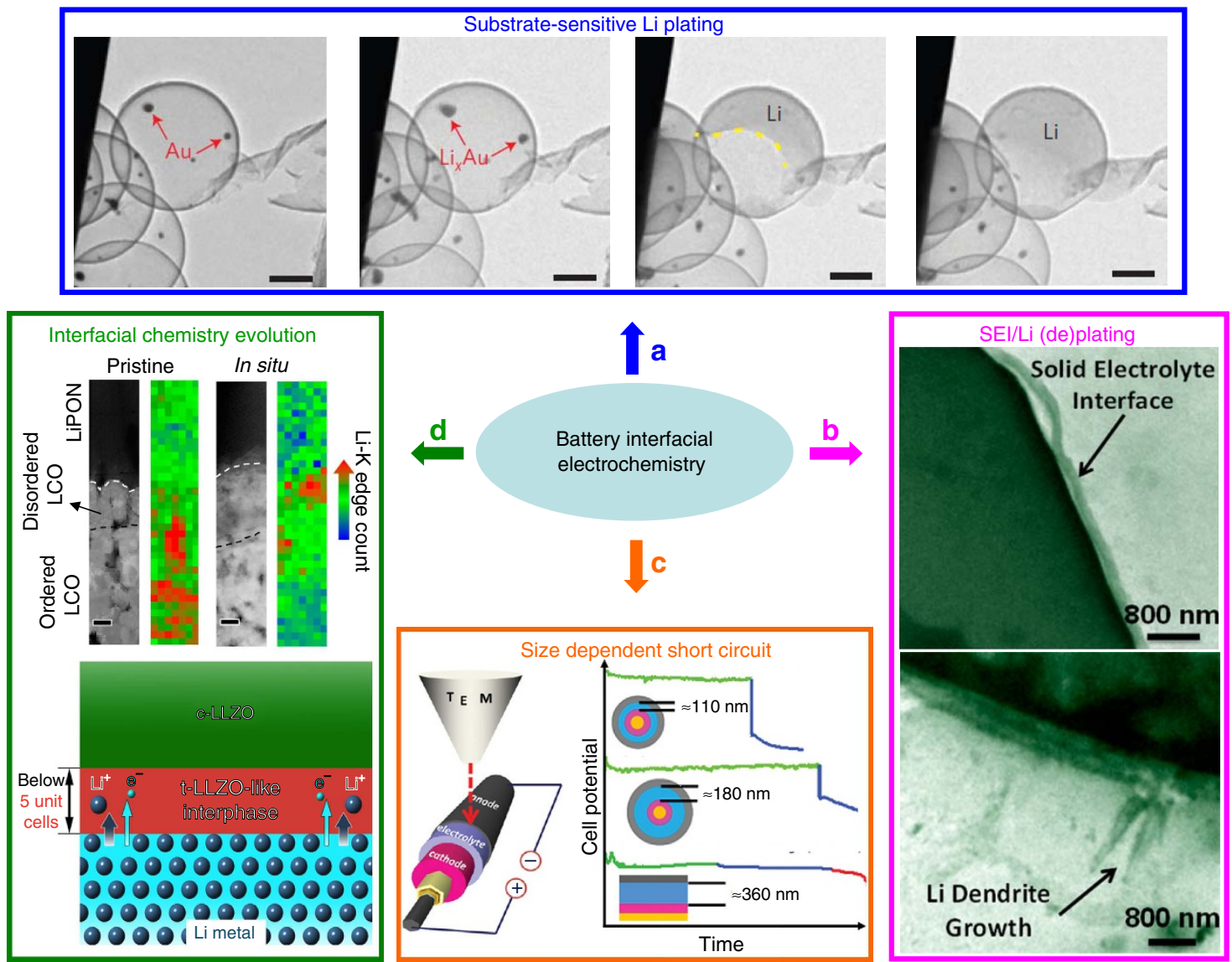

Figure 6 | Li plating and SEI evolution in both liquid electrolyte and solid electrolyte explored by in situ TEM. (a) Preferred Li deposition on Au. Scale bars, $200 \mathrm{~nm}$. Adapted from ref. 46 (Copyright 2016 Nature Publishing Group). (b) Nanoscale observation of SEl formation and Li dendrite growth on the electrode/liquid electrolyte interfaces ${ }^{49}$. Scale bars, $800 \mathrm{~nm}$. (c) Self-discharge of a battery controlled by the thickness of electrolyte (LiPON). Adapted from ref. 54 (Copyright 2012 American Chemical Society). (d) Chemical and electronic structure evolution at the interfaces of LiCoO $2 / L_{i P O N}$ (top; adapted from ref. 55, Copyright 2016 American Chemical Society) and $\mathrm{Li}_{(7-3 x)} \mathrm{Al}_{x} \mathrm{La}_{3} \mathrm{Zr}_{2} \mathrm{O}_{12} / \mathrm{Li}$ (bottom; reproduced from ref. 56, Copyright 2016 American Chemical Society) during cycling of thin-film solid-state batteries. Scale bar, $200 \mathrm{~nm}$.

modification/engineering of electrochemistry interfaces for improved battery performance. The application of protective layers carbon nanotube (CNT) on sulfur also demonstrated an efficient method to study electron beam-sensitive materials using TEM.

Rechargeable batteries with non-Li candidates. Alternative charge carriers are being extensively researched to replace $\mathrm{Li}$, whose storage in the earth's crust is too limited to meet the growing demand in the rechargeable battery market. $\mathrm{Na}^{+}$is a very promising candidate because of its rich storage in the earth as well as its relatively light atomic weight ${ }^{63}$. Multivalent ions such as $\mathrm{Mg}^{2+}, \mathrm{Ca}^{2+}$ and $\mathrm{Al}^{3+}$ are also studied as promising candidates to replace $\mathrm{Li}^{+}$because of their high-energy density ${ }^{64}$. However, because of the variation in electronegativities and ionic sizes, the dynamic (dis)charge process exhibits distinct features compared to that in lithium ion batteries. Dynamic study in this area is still at the preliminary stage and current findings are frequently compared to that from the intensively studied $\mathrm{Li}^{+}$-based electrochemistry.

It is of great significance to understand how $\mathrm{Na}^{+}$and $\mathrm{Li}^{+}$ transport in battery electrodes differently and result in distinct material behaviours and battery performance. As an alloying anode, Se exhibits a multistep alloying mechanism with inserted $\mathrm{Na}^{+}$, which sharply differs from the direct single-step Se-Li alloying process (Fig. $7 \mathrm{a})^{65}$. While similar intercalation mechanisms were observed for both lithiation and sodiation in
2D $\mathrm{MoS}_{2}$ (refs 66,67), distinct $\mathrm{Li}^{+} / \mathrm{Na}^{+}$intercalation behaviours were reported in $\alpha-\mathrm{MnO}_{2}$ possessing one-dimensional tunnels, where the tunnels are more vulnerable during intercalation of $\mathrm{Na}^{+}$ than $\mathrm{Li}^{+}$(Fig. 7b) ${ }^{68}$. For the conversion mechanism, the lithiation of $\mathrm{NiO}$ features a 'finger-like' heterogeneous reaction front ${ }^{69}$, while its sodiation is much delayed due to the 'shrinking-core' mode that thickens the $\mathrm{Na}_{2} \mathrm{O}$ surface layer and thus impedes further $\mathrm{Na}^{+}$ insertion (Fig. $7 \mathrm{c})^{70}$. Distinct features during lithiation and sodiation were also found in other conversion-based materials such as $\mathrm{CuO}$ (refs 34,71) and $\mathrm{FeF}_{2}$ (ref. 72). It is expected that the physical properties of the reaction interfaces should be responsible for the difference in reaction activities, structural stabilities and phase evolution during (de)lithiation and (de)sodiation, which apparently requires more fundamental study in the future.

Another notable difference between lithiation and sodiation is the mechanical response of materials considering the distinct sizes of $\mathrm{Na}^{+}(1.02 \AA)$ and $\mathrm{Li}^{+}(0.76 \AA)$. For example, the lithiation front in $\mathrm{SnO}_{2}$ nanowires features a dislocation-rich zone, making the lithiated $\mathrm{SnO}_{2}$ ductile and free of fracture, while $\mathrm{Na}^{+}$interact with the host much stronger and results in a softened structure of poor plasticity, high $\mathrm{Na}^{+}$diffusion barrier and disconnected Sn network, which largely decrease the sodiation kinetics (Fig. $7 \mathrm{~d})^{2,73}$. While such observation is reasonable, considering the much larger size of $\mathrm{Na}^{+}$over $\mathrm{Li}^{+}$, counterintuitive observations were reported for the sodiation and lithiation in Se (ref. 65), $\mathrm{Zn}_{4} \mathrm{Sb}_{3}$ (refs 74,75) and $\mathrm{Co}_{9} \mathrm{~S}_{8}$ 

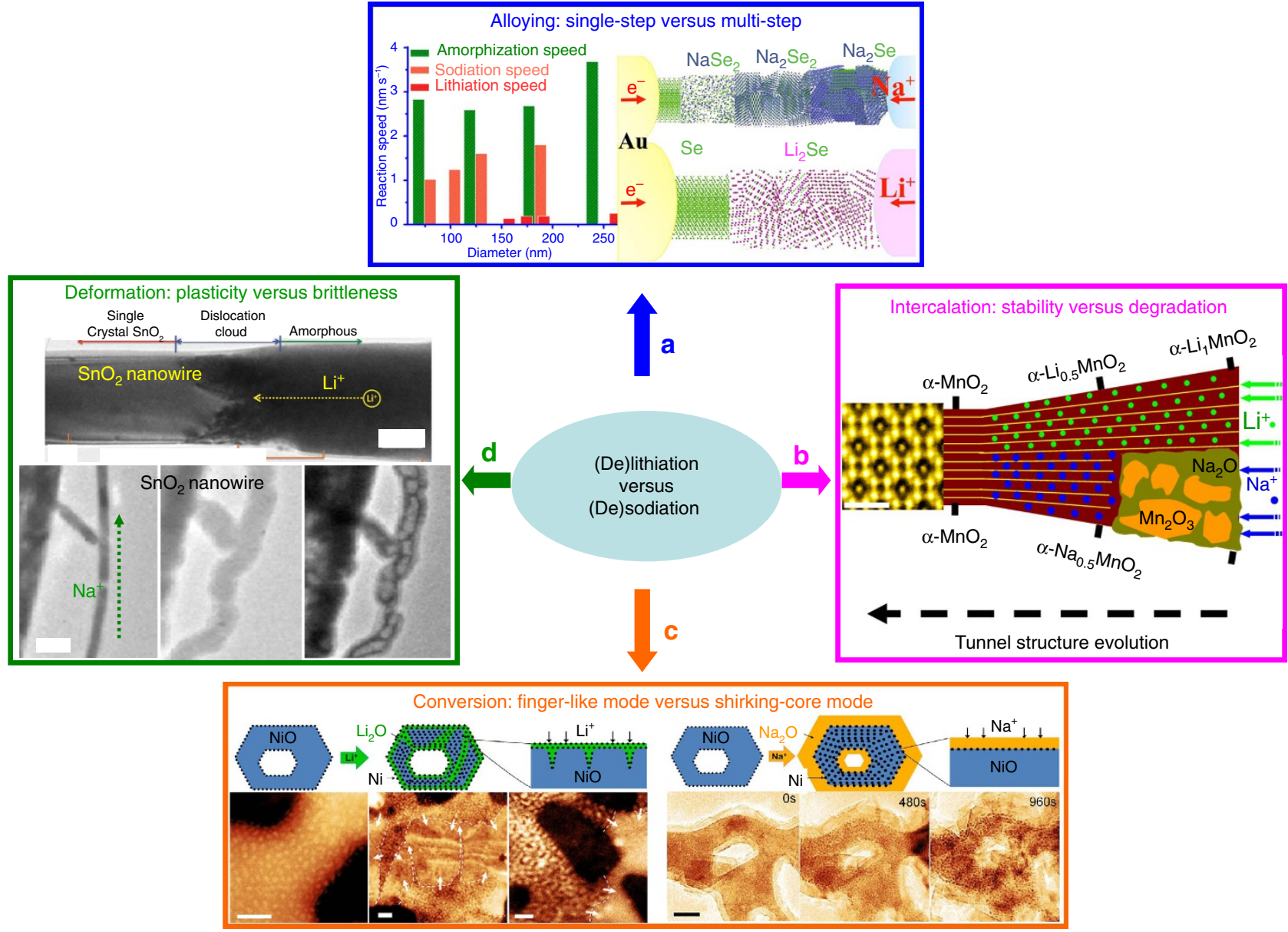

Figure 7 | In situ TEM research comparing (de)sodiation and (de)lithiation in various electrode materials. (a-c) Lithiation versus sodiation in alloying (Se)-, intercalation $\left(\mathrm{MnO}_{2}\right)$ - and conversion ( $\mathrm{NiO}$ )-based electrode materials, respectively. Scale bars in $\mathbf{c}$, 20nm. Panel a is reproduced from ref. 65 (Copyright 2016 American Chemical Society), b is adapted from ref. 68 (Copyright 2016 Elsevier Ltd.), c is adapted from ref. 69 (left) and ref. 70 (right) (Copyright 2015 American Chemical Society). (d) TEM images showing the lithiation-induced plasticity (top) and sodiation-induced softening/fracturing (bottom) in $\mathrm{SnO}_{2}$ nanowires. Scale bars, $200 \mathrm{~nm}$. Adapted from ref. 2 (top; Copyright 2010 American Associate for the Advancement of Science) and ref. 73 (bottom; Copyright 2013 American Chemical Society).

(refs 76,77), where sodiation proceeds faster than lithiation over one order of magnitude. The improved reaction kinetics in sodiation of such materials might be ascribed to the high electrical conductivity of the various phases involved ${ }^{74}$. This theory is important in guiding the design and engineering of advanced battery electrodes with improved (dis)charge kinetics by controlling the phase transition pathways or modifying the conductivity of involved phases properly.

To date, there are few in situ TEM reports successfully capturing the insertion of multivalent ions into electrode materials. $\mathrm{Ca}^{2}+$ was first reported to be electrochemically inserted into single crystalline $\mathrm{WO}_{3}$ films in TEM, where an intercalation step $\left(\mathrm{Ca}_{x} \mathrm{WO}_{3}\right)$ prior to conversion of $\mathrm{WO}_{3}$ into $\mathrm{W}$ and $\mathrm{CaO}$ was explicitly revealed at atomic scale ${ }^{78}$. In the case of $\mathrm{Co}_{3} \mathrm{O}_{4}$ nanocubes, $\mathrm{Mg}^{2+}$ insertion shows no sign of conversion reaction other than $\mathrm{Mg}$ plating, while $\mathrm{Al}^{3+}$ insertion is even more sluggish ${ }^{79}$. Such sluggish kinetics are largely determined by the inactive solid-state oxide layers $\left(\mathrm{MgO}\right.$ and $\left.\mathrm{Al}_{2} \mathrm{O}_{3}\right)$ covering the surface of metallic anodes, as well as the large repulsive forces encountered by the inserted cations.

Electron beam effect and electrochemistry in TEM. The energy of an incident electron during TEM operation ranges from tens to hundreds of KeVs, which can trigger side reactions in targeted materials and adversely affect the imaging process. The typical negative effects include atomic displacement and e-beam sputtering caused by elastic (electron-nucleus) scattering, and specimen heating/contamination/damage due to inelastic scattering ${ }^{80}$. Different materials exhibit distinct stability characteristics depending on the bonding strength between atoms, the mass of each element and the imaging condition. The extent by which the beam can affect any given material during the imaging process is a function of the beam-incident electron energy, dose rate and beam probe diameter. Such threshold values have been previously discussed and quantified ${ }^{80}$. Since a working battery requires the presence of electron transfer and the general usage of hydrocarbon-based materials that are sensitive to electron beam, the effects of an electron beam on in situ observation should be taken into serious consideration. These effects also vary based on different in situ TEM designs as categorized below.

Beam effect on solid-state open cell design. Within the solidstate open cell, the main concern is the stability of $\mathrm{Li}_{2} \mathrm{O}$ under electron beam and the subsequent effect on the observed battery electrochemistry. The electron beam was reported to either slow down the electrochemical lithiation (Fig. $8 \mathrm{a})^{3}$ or initiate the chemical lithiation (Fig. 8b) by decomposing $\mathrm{Li}_{2} \mathrm{O}$ to release $\mathrm{Li}$ and lithiate nearby electrodes ${ }^{5}$. Fortunately, such decomposition 


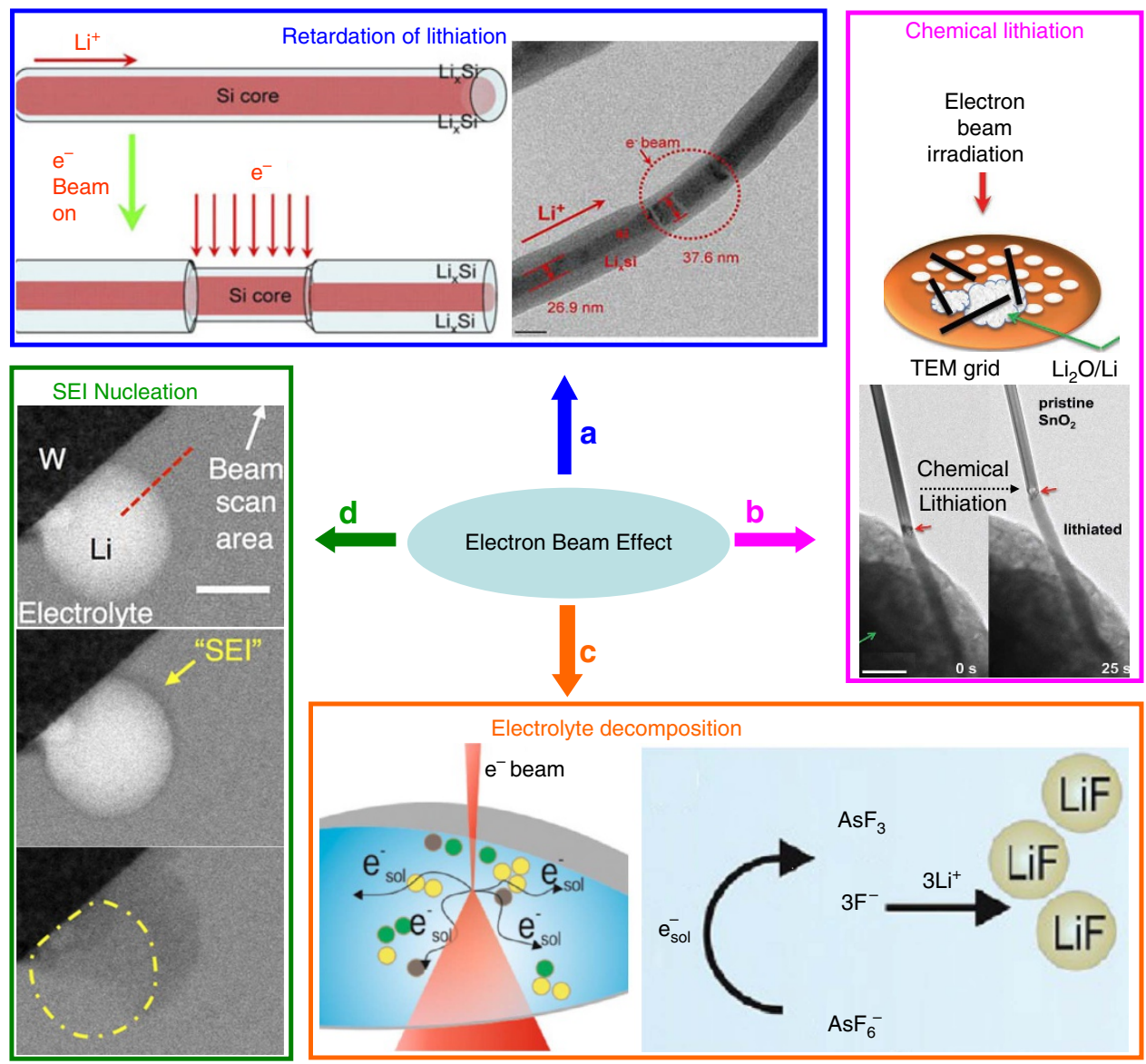

Figure 8 | Electron beam effect on in situ TEM of battery electrochemistry. (a) Retardation of lithiation in a Si nanowire by electron beam. Scale bar, $50 \mathrm{~nm}$. Adapted from ref. 3 (Copyright 2014 Materials Research Society). (b) Lithiation of a $\mathrm{SnO}_{2}$ nanowire driven by beam-induced $\mathrm{Li}_{2} \mathrm{O}$ decomposition. Scale bar, $500 \mathrm{~nm}$. Adapted from ref. 5 (Copyright 2012 WILEY-VCH Verlag GmbH \& Co. KGaA, Weinheim). (c) Schematics of beam-induced electrolyte decomposition as well as the proposed reduction mechanism of $\mathrm{LiAsF}_{6}$ in organic solvents. Adapted from ref. 82 (Copyright 2014 American Chemical Society). (d) Beam-induced SEl growth on the surface of Li deposit and at the expense of Li stripping. Scale bar, $300 \mathrm{~nm}$. Adapted from ref. 48 (Copyright 2015 American Chemical Society).

can be alleviated by reducing the electron dosage below the safe dosage $\sim 1 \mathrm{~A} \mathrm{~cm}^{-2}$, and the chemical lithiation can thus be suppressed ${ }^{5}$. To further clarify the electron beam effect, contrast experiments have been done by controlling the electron energy and dosage, blocking the electron beam while not recording ${ }^{5}$ and referring to ex situ characterizations ${ }^{19}$. It is generally accepted that the material behaviours observed by in situ TEM using the open cell design could reflect the real battery electrochemistry in terms of reaction kinetics, structural change and chemical evolution ${ }^{81}$.

Beam effect on sealed liquid-cell design. Compared to the solid open cell, the in situ liquid-cell TEM is subject to more side reactions such as electrolyte breakdown ${ }^{82}$, bubble formation ${ }^{83}$ and nanoparticles' precipitation/dissolution ${ }^{82,84}$. A range of (non)aqueous/Li salt electrolytes relevant to state-of-the-art Li-ion battery systems have been tested regarding their stability under electron beam ${ }^{82,85}$. In aqueous solutions, electron beam could generate various gases (bubbles) and free radicals that potentially affect the battery electrochemistry ${ }^{85}$. Browning and co-workers ${ }^{82}$ systematically studied electron beam radiolysis on nonaqueous electrolytes such as $\mathrm{LiAsF}_{6}$ in dioxolane (DOL), dimethyl carbonate (DMC) and $\mathrm{DMC}+\mathrm{EC}$, as well as LiTf in dimethylsulphoxide and $\mathrm{LiPF}_{6}$ in $\mathrm{EC} / \mathrm{DMC}$. A per-frame dose of $13.7 \mathrm{e}^{-} \mathrm{nm}^{-2} \mathrm{f}$ is sufficient to cause breakdown of $\mathrm{LiAsF}_{6}$-based electrolytes with precipitation of $\mathrm{LiF}$ nanoparticles in the solution
(Fig. 8c). $\mathrm{LiPF}_{6}$-based electrolyte is more stable as evidenced by the formation of fewer and smaller nanoparticles, while the LiTfbased electrolyte is very stable without any sign of breakdown. The observed stability variation among various electrolytes and the breakdown products and mechanisms agree with the ex situ battery tests, indicating the possibility of directly probing electrolyte stability using the in situ liquid scanning transmission electron microscopy technique. Following the decomposition of electrolytes $\left(\mathrm{LiPF}_{6} / \mathrm{EC} / \mathrm{DMC}\right)$ under electron beam, other researchers also captured SEI nucleation and growth on Li deposit (Fig. 8d) ${ }^{48}$. The suitability of applying liquid TEM in real battery study is further demonstrated by obtaining the similar cyclic voltammetry $(\mathrm{CV})$ curves with the beam on and off when testing nonaqueous electrolyte-based electrochemistry ${ }^{10}$.

\section{Perspectives for in situ TEM of rechargeable batteries}

Quantitative analysis to mimic ex situ battery testing. The quantification of nanoscale electrochemistry inside TEM is critical to correlate structural changes with the electrical output at various states of (dis)charge. While most in situ TEM research focuses on material analysis under constant voltages, better correlation with battery electrochemistry should be pursued. It is thus important to carry out real battery tests such as galvanostatic (dis)charge, CV, choronoamperometry and electrochemical 
impedance spectroscopy inside TEM. Recent reports have shown the possibility of measuring pA-level current flowing through a single nanowire-based battery ${ }^{9}$, observing small-scale SEI evolution and $\mathrm{Li}$ (de)plating in microfluidic TEM cells for galvanostatic $^{48}$ and CV studies ${ }^{86}$. In extending the nanoscale findings to bulk-level battery electrochemistry, it is necessary to consider the impact of material interfaces and size effects on mass transfer and transport ${ }^{87}$. Future work should thus incorporate more details about the effect of cell dimension, geometrical electrode configurations and microfluidic conditions on the accuracy of electrochemistry quantification.

Electrochemical evaluation under complex environment. With recent developments in the design of microfluidic and electromechanical chips and TEM column configurations, microscopists now can study electrochemical reactions in more complex environments. For instance, with the introduction of a thin-film heater within liquid cells, it would be quite interesting to study electrochemical reactions at various temperatures to understand the nature and composition of SEI growth as a function of temperature. These studies can also provide new understanding about the origins of thermal failure in rechargeable ion batteries. Another interesting study would be to introduce oxygen or water vapour in environmental TEM equipped with open cell battery holders to track the structural and chemical evolution of SSEs. This can help electrochemists to explore the degradation mechanisms accounting for the failure of solid-state batteries in ambient atmosphere. Including force measurement features in the electrochemical holders can be used to quantitatively explore the mechanical degradation in flexible batteries. Ion irradiation in TEM during electrochemical reactions can help us gain a better understanding of the working environment of delicate batteries widely used in aerospace and nuclear environments. These environments are rich in intensive ion flux, which can potentially result in ionization, atomic displacement, impurity production and energy release ${ }^{88}$.

Electrochemistry studies with multiprobes. With the advent of new detection and imaging probes in TEMs, innovative windows of opportunities can be opened towards understanding the underlying mechanisms of complex electrochemical reactions. A direct observation of charge distribution under batteryoperating conditions is important to assess interior potential distribution. Off-axis electron holography has been recently incorporated with in situ TEM to image the charge distribution in Ge nanowire during normal (de)lithiation ${ }^{89}$. Inspired by this design, future work can focus on exploring more about electrochemical dynamics that involve ion insertion and electron transport under battery-operating condition. The development of ultrahigh-speed cameras (up to $1,600 \mathrm{fps})^{90}$ is necessary considering the beam-sensitive nature of many battery components such as lithium and sodium salts, carbon-based materials and the liquid electrolyte. Imaging under even higher temporal resolution of nanoseconds is also necessary if one desires to visualize the transient atomic motions such as the breaking and formation of chemical bonds to understand the ultrafast structural dynamics $^{91,92}$. This is also suitable for TEM studies of dynamic events under extremely cyclic/oscillatory conditions. Such high time resolution can be achieved via utilization of a pulsed electron beam, and this technique is ultimately limited by the ability of generating enough electron flux from the gun source ${ }^{90}$.

In addition to electrons, signals such as photons and secondary ions can also be generated in TEM. The capability of introducing light (laser) and simultaneously collecting the excited photons from targeted materials has been demonstrated previously for both
Raman and cathodoluminescence spectroscopies ${ }^{93,94}$. Applying such techniques to battery systems, one can expect the real-time monitoring of battery temperature, chemical and compositional evolution and defect localization during the battery cycling inside TEM. Secondary ion mass spectroscopy has been developed to dynamically study electrochemistry interfaces buried in liquid electrolyte due to its sensitivity to the surface composition, molecular structure and elemental (especially for $\mathrm{H}$ and $\mathrm{Li}$ ) distribution ${ }^{95}$. The previous work of synergizing focused ion beam (FIB) (for incident ions) and secondary ion mass spectroscopy (for secondary ion detection) within $\mathrm{TEM}^{96}$ has enlightened the possible incorporation of this technique for real-time battery study using in situ liquid-cell TEM, which can provide systematic information regarding interfacial dynamics and kinetics. However, the introduction of multistimuli and multiprobes into the narrow gap between the two pole pieces within TEM can potentially degrade the imaging resolution and increase the chance of cross-contamination, which will demand a careful design of the hardware configuration.

Pushing towards high resolutions. One problem plaguing the in situ TEM community is the reduced spatial/energy resolution due to presence of membranes for microfluidic devices, thick liquid electrolytes or various stimuli along the beam path, which largely decrease the accuracy of imaging or spectroscopy analyses. In particular, the spatial resolution of the liquid cell falls far behind that of traditional imaging, not to mention the elemental and electronic structure sensitivity ${ }^{97}$. Therefore, future work should aim to increase the spatial resolution and the analytical ability of in situ TEM by reducing the liquid thickness along the electron path, replacing the thick SiN windows with thinner layers ${ }^{98}$, and engineering the pathway of characteristic X-rays travelling to the detector ${ }^{99}$. Another promising method recently developed for high-resolution imaging through liquid electrolyte is the use of atomically thin graphene to encapsulate a limited amount of liquid and form a sealed environment for in situ observation ${ }^{100,101}$. This strategy greatly reduces inelastic electron scattering and guarantees atomic-level imaging through the liquid. However, the thinner thicknesses mean that one should also consider the effect of confined volumes ${ }^{87}$ on the electrochemical reactions and how such reactions differ with the ones occurring at larger length scales.

In situ TEM for future battery chemistries. With everyday progress in the field of in situ TEM, it is becoming important to tackle some of the scientific challenges that new battery chemistries are facing. For example, the study of $\mathrm{Li}-\mathrm{O}_{2}$ batteries using in situ liquid TEM is very difficult because of the practical difficulty of introducing $\mathrm{O}_{2}$ in the TEM chamber. This complicated system, however, was simplified by flowing an $\mathrm{O}_{2}$-rich electrolyte into the liquid cell in TEM ${ }^{60}$. This opens up the idea for exploring the ORR and OER in subnanoscale. It would be of great interest to further investigate the charge/discharge reactions in $\mathrm{Na}-\mathrm{O}_{2}$ and $\mathrm{Zn}-\mathrm{O}_{2}$ batteries that have high chance of major breakthroughs. Another interesting chemistry would be the high-voltage aqueous electrolyte Li-ion batteries that have been realized by the 'water-in-salt' concept ${ }^{102}$. In situ liquid TEM experiments can probably replace the currently used organic electrolyte with aqueous electrolytes. This can ease the operational challenges of organic-based liquid electrolytes such as carbon contamination, liquid flow clogging and $\mathrm{H}_{2} \mathrm{O}$-sensitive organic electrolyte. The study of multivalent batteries can be pursued with a liquid-cell TEM technique and with a proper choice of electrolytes and electrodes. 
In addition to several promising directions to be further explored by in situ TEM, one should realize the limitations of this technique. These include the requirement of delicate specimens with extremely thin thicknesses, minimized contamination and maximized stability, as well as the effect of confined volumes on the electrochemical reactions. With these considerations, it is necessary to combine other complementary methods (for example, in situ X-ray scattering and Raman spectroscopy) with in situ TEM to enable a more comprehensive evaluation of dynamic electrochemical reactions.

To conclude, we have summarized the current scientific discoveries in rechargeable batteries ( $\mathrm{Li}-\mathrm{ion}, \mathrm{Li}-\mathrm{O}_{2}, \mathrm{Li}-\mathrm{S}$ and $\mathrm{Na}$-ion batteries) that have been realized by in situ TEM. Compared to other in situ techniques, TEM enables direct visualization and spectroscopy of the electrochemical processes at subnanoscales. The sensitivity of TEM in capturing localized information and inhomogeneity also complements other in situ methods sensitive to bulk information. Significant findings include, but are not limited to, the positive role of crystal defects in charge transport, anisotropic lithiation, phase boundary migration kinetics during cycling, SEI and metallic dendrite evolution in liquid electrolytes, and the key factors limiting the ORR and OER kinetics in metal-air batteries. We foresee that in situ TEM holds great potential to further advance our fundamental knowledge of nanoscale electrochemistry events in rechargeable ion batteries. Along these lines, multidimensional and cross-disciplinary efforts from electrochemists, microscopists and nanofabrication scientists are needed to address the current battery challenges and pave the roadmap for new discoveries in this field. Some of the future directions can encompass (1) performing quantitative electrochemistry at nanoscale; (2) advancing multiprobe analysis during nanoscale electrochemistry; (3) developing new stimuli to study batteries under nonequilibrium environments; (4) enhancing the image resolutions; and (5) exploring the challenges of new battery chemistries beyond $\mathrm{Li}$-ion batteries.

\section{References}

1. Erickson, E. M., Ghanty, C. \& Aurbach, D. New horizons for conventional lithium ion battery technology. J. Phys. Chem. Lett. 5, 3313-3324 (2014).

2. Huang, J. et al. In situ observation of the electrochemical lithiation of a single $\mathrm{SnO}_{2}$ nanowire electrode. Science 330, 1515-1520 (2010).

This paper reports for the first time the dynamics of litiated-unlithiated reaction front in a $\mathrm{SnO}_{2}$ nanowire inside a transmission electron microscope.

3. Wang, C. In situ transmission electron microscopy and spectroscopy studies of rechargeable batteries under dynamic operating conditions: a retrospective and perspective view. J. Mater. Res. 30, 326-339 (2015).

4. Gu, M., He, Y., Zheng, J. \& Wang, C. Nanoscale silicon as anode for Li-ion batteries: the fundamentals, promises, and challenges. Nano Energy 17, 366-383 (2015).

5. Liu, X. et al. In situ TEM experiments of electrochemical lithiation and delithiation of individual nanostructures. Adv. Energy Mater. 2, 722-741 (2012).

6. Tarascon, J. M. \& Armand, M. Issues and challenges facing rechargeable lithium batteries. Nature 414, 359-367 (2001).

7. Poizot, P., Laruelle, S., Grugeon, S., Dupont, L. \& Tarascon, J. M. Nano-sized transition-metal oxides as negative-electrode materials for lithium-ion batteries. Nature 407, 496-499 (2000).

8. Yuan, Y. et al. Asynchronous crystal cell expansion during lithiation of $\mathrm{K}^{+}$-stabilized $\alpha-\mathrm{MnO}_{2}$. Nano Lett. 15, 2998-3007 (2015).

This paper reveals the dynamics of $\mathrm{Li}^{+}$transport in transitional metal oxides that possess one-dimensional tunnels and how the atomistic mechanisms affect the overall battery performance.

9. Lee, $\mathrm{S}$. et al. Phase transitions in a $\mathrm{LiMn}_{2} \mathrm{O}_{4}$ nanowire battery observed by operando electron microscopy. ACS Nano 9, 626-632 (2014).

10. Holtz, M. E. et al. Nanoscale imaging of lithium ion distribution during in situ operation of battery electrode and electrolyte. Nano Lett. 14, 1453-1459 (2014).

11. Niu, J. et al. In situ observation of random solid solution zone in $\mathrm{LiFePO}_{4}$ electrode. Nano Lett. 14, 4005-4010 (2014).
12. Zhu, Y. et al. In situ atomic-scale imaging of phase boundary migration in $\mathrm{FePO}_{4}$ microparticles during electrochemical lithiation. Adv. Mater. 25, 5461-5466 (2013).

13. Wang, Z. et al. Electron-rich driven electrochemical solid-state amorphization in Li-Si alloys. Nano Lett. 13, 4511-4516 (2013).

14. Liu, X. et al. Size-dependent fracture of silicon nanoparticles during lithiation. ACS Nano 6, 1522-1531 (2012).

15. Liu, X. et al. Self-limiting lithiation in silicon nanowires. ACS Nano 7, 1495-1503 (2013).

16. Liu, X. et al. Anisotropic swelling and fracture of silicon nanowires during lithiation. Nano Lett. 11, 3312-3318 (2011).

17. Liu, X. et al. In situ atomic-scale imaging of electrochemical lithiation in silicon. Nat. Nanotechnol. 7, 749-756 (2012).

This paper reports the atomistic behaviors of electrochemical interfaces during the lithation of crystalline silicon.

18. Janish, M. T. et al. TEM in situ lithiation of tin nanoneedles for battery applications. J. Mater. Sci. 51, 589-602 (2016).

19. Liu, X. et al. Reversible nanopore formation in Ge nanowires during lithiation-delithiation cycling: an in situ transmission electron microscopy study. Nano Lett. 11, 3991-3997 (2011).

20. Leenheer, A. J., Jungiohann, K. L., Zavadil, K. R. \& Harris, C. T. Phase boundary propagation in Li-alloying battery electrodes revealed by liquid-cell transmission electron microscopy. ACS Nano 10, 5670-5678 (2016).

21. Wu, H. \& Cui, Y. Designing nanostructured Si anodes for high energy lithium ion batteries. Nano Today 7, 414-429 (2012).

22. Liu, N. et al. A pomegranate-inspired nanoscale design for large-volumechange lithium battery anodes. Nat. Nanotechnol. 9, 187-192 (2014).

23. Li, X. et al. Mesoporous silicon sponge as an anti-pulverization structure for high-performance lithium-ion battery anodes. Nat. Commun. 5, 4105 (2014).

24. Zhang, Z. et al. Scalable synthesis of interconnected porous silicon/carbon composites by the rochow reaction as high-performance anodes of lithium ion batteries. Angew. Chem. 126, 5265-5269 (2014).

25. Wu, H. et al. Stable Li-ion battery anodes by in-situ polymerization of conducting hydrogel to conformally coat silicon nanoparticles. Nat. Commun. 4, 1943 (2013).

26. Luo, L., Wu, J., Xu, J. \& Dravid, V. P. Atomic resolution study of reversible conversion reaction in metal oxide electrodes for lithium-ion battery. ACS Nano 8, 11560-11566 (2014).

27. Su, Q. et al. In situ transmission electron microscopy observation of electrochemical behavior of $\mathrm{CoS}_{2}$ in lithium-ion battery. ACS Appl. Mater. Interfaces 6, 3016-3022 (2014).

28. Liu, S. et al. Understanding Li-storage mechanism and performance of $\mathrm{MnFe}_{2} \mathrm{O}_{4}$ by in situ TEM observation on its electrochemical process in nano lithium battery. Nano Energy 8, 84-94 (2014).

29. Wang, F. et al. Tracking lithium transport and electrochemical reactions in nanoparticles. Nat. Commun. 3, 1201 (2012).

30. He, K. et al. Visualizing non-equilibrium lithiation of spinel oxide via in situ transmission electron microscopy. Nat. Commun. 7, 11441 (2016). This paper reveals the non-equilibrium lithiation pathways in spinel $\mathrm{Fe}_{3} \mathrm{O}_{4}$ and correlates the intermediate phase transitions with the battery performance.

31. Li, Y., Sun, H., Cheng, X., Zhang, Y. \& Zhao, K. In-situ TEM experiments and first-principles studies on the electrochemical and mechanical behaviors of $\alpha-\mathrm{MoO}_{3}$ in Li-ion batteries. Nano Energy 27, 95-102 (2016).

32. Gregorczyk, K. E., Liu, Y., Sullivan, J. P. \& Rubloff, G. W. In situ transmission electron microscopy study of electrochemical lithiation and delithiation cycling of the conversion anode $\mathrm{RuO}_{2}$. ACS Nano 7, 6354-6360 (2013).

33. Su, Q., Xie, D., Zhang, J., Du, G. \& Xu, B. In situ transmission electron microscopy observation of the conversion mechanism of $\mathrm{Fe}_{2} \mathrm{O}_{3} /$ graphene anode during lithiation-delithiation processes. ACS Nano 7, 9115-9121 (2013).

34. Wang, $\mathrm{X}$. et al. Revealing the conversion mechanism of $\mathrm{CuO}$ nanowires during lithiation-delithiation by in situ transmission electron microscopy. Chem. Commun. 48, 4812-4814 (2012).

35. Shan, X. et al. Visualizing the roles of graphene for excellent lithium storage. J. Mater. Chem. A 2, 17808-17814 (2014).

36. Gu, M. et al. In situ TEM study of lithiation behavior of silicon nanoparticles attached to and embedded in a carbon matrix. ACS Nano 6, 8439-8447 (2012).

37. Wang, C. et al. In situ TEM investigation of congruent phase transition and structural evolution of nanostructured silicon/carbon anode for lithium ion batteries. Nano Lett. 12, 1624-1632 (2012).

38. Li, Y. et al. Growth of conformal graphene cages on micrometre-sized silicon particles as stable battery anodes. Nat. Energy 1, 15029 (2016).

39. Liu, N. et al. A yolk-shell design for stabilized and scalable Li-ion battery alloy anodes. Nano Lett. 12, 3315-3321 (2012).

This paper reports a novel design of hollow carbon structure which 
effectively addresses the problems in silicon anode in terms of its large volumetric variation during cycling.

40. Lu, X., Bogart, T. D., Gu, M., Wang, C. \& Korgel, B. A. In situ TEM observations of $\mathrm{Sn}$-containing silicon nanowires undergoing reversible pore formation due to fast lithiation/delithiation kinetics. J. Phys. Chem. C 119, 21889-21895 (2015)

41. Liu, Y. et al. Tailoring lithiation behavior by interface and bandgap engineering at the nanoscale. Nano Lett. 13, 4876-4883 (2013).

42. Nie, A. et al. Twin boundary-assisted lithium ion transport. Nano Lett. 15, 610-615 (2015).

43. Hwang, S. et al. Investigating local degradation and thermal stability of charged nickel-based cathode materials through real-time electron microscopy. ACS Appl. Mater. Interfaces 6, 15140-15147 (2014).

44. Hwang, S. et al. Using real-time electron microscopy to explore the effects of transition-metal composition on the local thermal stability in charged $\mathrm{Li}_{\mathrm{x}} \mathrm{Ni}_{\mathrm{y}} \mathrm{Mn}_{\mathrm{z}} \mathrm{Co}_{1-\mathrm{y}-\mathrm{z}} \mathrm{O}_{2}$ cathode materials. Chem. Mater. 27, 3927-3935 (2015).

45. Sharifi-Asl, S. et al. Facet-dependent thermal instability in $\mathrm{LiCoO}_{2}$. Nano Lett. 17, 2165-2171 (2017).

46. Yan, K. et al. Selective deposition and stable encapsulation of lithium through heterogeneous seeded growth. Nat. Energy 1, 16010 (2016).

This paper demosntrates the succeessful control of lithium plating by doping the anode with various metallic seeds.

47. Zheng, G. et al. Interconnected hollow carbon nanospheres for stable lithium metal anodes. Nat. Nanotechnol. 9, 618-623 (2014).

48. Leenheer, A. J., Jungjohann, K. L., Zavadil, K. R., Sullivan, J. P. \& Harris, C. T. Lithium electrodeposition dynamics in aprotic electrolyte observed in situ via transmission electron microscopy. ACS Nano 9, 4379-4389 (2015). The electrochemical deposition/dissolution of lithium metal is dynamically recorded through a liquid environment containing aprotic electrolyte.

49. Zeng, Z. et al. Visualization of electrode-electrolyte interfaces in $\mathrm{LiPF}_{6} / \mathrm{EC} /$ DEC electrolyte for lithium ion batteries via in situ TEM. Nano Lett. 14, 1745-1750 (2014).

50. Kushima, A. et al. Liquid cell transmission electron microscopy observation of lithium metal growth and dissolution: root growth, dead lithium and lithium flotsams. Nano Energy 32, 271-279 (2017).

51. Mehdi, B. L. et al. Observation and quantification of nanoscale processes in lithium batteries by operando electrochemical (S)TEM. Nano Lett. 15, 2168-2173 (2015).

52. Sacci, R. L. et al. Direct visualization of initial SEI morphology and growth kinetics during lithium deposition by in situ electrochemical transmission electron microscopy. Chem. Commun. 50, 2104-2107 (2014).

53. Wang, Y. et al. Design principles for solid-state lithium superionic conductors. Nat. Mater. 14, 1026-1031 (2015).

54. Ruzmetov, D. et al. Electrolyte stability determines scaling limits for solidstate 3D Li ion batteries. Nano Lett. 12, 505-511 (2011).

55. Wang, Z. et al. In situ STEM-EELS observation of nanoscale interfacial phenomena in all-solid-state batteries. Nano Lett. 16, 3760-3767 (2016).

56. Ma, C. et al. Interfacial stability of Li metal-solid electrolyte elucidated via in situ electron microscopy. Nano Lett. 16, 7030-7036 (2016).

This paper reports the chemical and structural evolution of electrochemical interphases existing in the interface region between a lithium anode and a solid state electrolyte.

57. Yamamoto, K. et al. Dynamic visualization of the electric potential in an all-solid-state rechargeable lithium battery. Angew. Chem., Int. Ed. 49, 4414-4417 (2010).

58. Bruce, P. G., Freunberger, S. A., Hardwick, L. J. \& Tarascon, J. M. Li-O $\mathrm{O}_{2}$ and Li-S batteries with high energy storage. Nat. Mater. 11, 19-29 (2012).

59. Zhong, L. et al. In situ transmission electron microscopy observations of electrochemical oxidation of $\mathrm{Li}_{2} \mathrm{O}_{2}$. Nano Lett. 13, 2209-2214 (2013).

60. Kushima, A. et al. Charging/discharging nanomorphology asymmetry and rate-dependent capacity degradation in Li-oxygen battery. Nano Lett. 15, 8260-8265 (2015).

61. Xu, R. et al. Insight into sulfur reactions in Li-S batteries. ACS Appl. Mater. Interface 6, 21938-21945 (2014).

62. Kim, H. et al. In situ TEM observation of electrochemical lithiation of sulfur confined within inner cylindrical pores of carbon nanotubes. Adv. Energy Mater. 5, 1501306 (2015).

63. Yabuuchi, N., Kubota, K., Dahbi, M. \& Komaba, S. Research development on sodium-ion batteries. Chem. Rev. 114, 11636-11682 (2014).

64. Lin, M. C. et al. An ultrafast rechargeable aluminium-ion battery. Nature 520, 324-328 (2015).

65. Li, Q. et al. Electrochemistry of selenium with sodium and lithium: kinetics and reaction mechanism. ACS Nano 10, 8788-8795 (2016).

66. Wang, L., Xu, Z., Wang, W. \& Bai, X. Atomic mechanism of dynamic electrochemical lithiation processes of $\mathrm{MoS}_{2}$ nanosheets. J. Am. Chem. Soc. 136, 6693-6697 (2014).
67. Gao, P., Wang, L., Zhang, Y., Huang, Y. \& Liu, K. Atomic-scale probing of the dynamics of sodium transport and intercalation-induced phase transformations in $\mathrm{MoS}_{2}$. ACS Nano 9, 11296-11301 (2015).

68. Yuan, Y. et al. Dynamic study of (De)sodiation in alpha- $\mathrm{MnO}_{2}$ nanowires. Nano Energy 19, 382-390 (2016).

69. He, K. et al. Transitions from near-surface to interior redox upon lithiation in conversion electrode materials. Nano Lett. 15, 1437-1444 (2015).

70. He, K. et al. Sodiation kinetics of metal oxide conversion electrodes: a comparative study with lithiation. Nano Lett. 15, 5755-5763 (2015).

71. Zhang, L. et al. In situ transmission electron microscopy study of the electrochemical sodiation process for a single $\mathrm{CuO}$ nanowire electrode RSC Adv. 6, 11441-11445 (2016)

72. He, K. et al. Sodiation via heterogeneous disproportionation in $\mathrm{FeF}_{2}$ electrodes for sodium-ion batteries. ACS Nano 8, 7251-7259 (2014).

73. $\mathrm{Gu}, \mathrm{M}$. et al. Probing the failure mechanism of $\mathrm{SnO}_{2}$ nanowires for sodium-ion batteries. Nano Lett. 13, 5203-5211 (2013).

74. Nie, A. et al. Ultrafast and highly reversible sodium storage in zinc-antimony intermetallic nanomaterials. Adv. Funct. Mater. 26, 543-552 (2016).

75. Nie, A. et al. Lithiation-induced shuffling of atomic stacks. Nano Lett. 14, 5301-5307 (2014)

76. Su, Q. et al. In situ transmission electron microscopy observation of electrochemical sodiation of individual $\mathrm{Co}_{9} \mathrm{~S}_{8}$-filled carbon nanotubes. ACS Nano 8, 3620-3627 (2014).

77. Su, Q. et al. In situ transmission electron microscopy investigation of the electrochemical lithiation-delithiation of individual $\mathrm{Co}_{9} \mathrm{~S}_{8} / \mathrm{Co}$-filled carbon nanotubes. ACS Nano 7, 11379-11387 (2013).

78. He, Y. et al. Atomistic conversion reaction mechanism of $\mathrm{WO}_{3}$ in secondary ion batteries of $\mathrm{Li}, \mathrm{Na}$, and $\mathrm{Ca}$. Angew. Chem. Int. Ed. 55, 6244-6247 (2016).

This paper reveals for the first time the existence of an intercalation step prior to the conversion of $\mathrm{WO}_{3}$ electrode during the insertion of $\mathrm{Li}^{+}, \mathrm{Na}^{+}$ and $\mathrm{Ca}^{2+}$ ions.

79. Luo, L. et al. Reactions of graphene supported $\mathrm{Co}_{3} \mathrm{O}_{4}$ nanocubes with lithium and magnesium studied by in situ transmission electron microscopy. Nanotechnology 27, 085402 (2016).

80. Egerton, R., Li, P. \& Malac, M. Radiation damage in the TEM and SEM. Micron 35, 399-409 (2004).

81. Gao, Q. et al. Direct evidence of lithium-induced atomic ordering in amorphous $\mathrm{TiO}_{2}$ nanotubes. Chem. Mater. 26, 1660-1669 (2014)

82. Abellan, P. et al. Probing the degradation mechanisms in electrolyte solutions for Li-ion batteries by in situ transmission electron microscopy. Nano Lett. 14, 1293-1299 (2014)

83. Ross, F. M. Opportunities and challenges in liquid cell electron microscopy. Science 350, aaa9886 (2015).

84. Yuan, Y. et al. Atomistic insights into the oriented attachment of tunnel-based oxide nanostructures. ACS Nano 10, 539-548 (2016).

85. Schneider, N. M. et al. Electron-water interactions and implications for liquid cell electron microscopy. J. Phys. Chem. C 118, 22373-22382 (2014).

86. Sacci, R. L. et al. Nanoscale imaging of fundamental Li battery chemistry: solid-electrolyte interphase formation and preferential growth of lithium metal nanoclusters. Nano Lett. 15, 2011-2018 (2015).

87. Maier, J. Nanoionics: ion transport and electrochemical storage in confined systems. Nat. Mater. 4, 805-815 (2005).

88. Nagatani, K. et al. Emergency response to the nuclear accident at the Fukushima Daiichi nuclear power plants using mobile rescue robots. J. Field. Robot. 30, 44-63 (2013)

89. Gan, Z. et al. Direct mapping of charge distribution during lithiation of Ge nanowires using off-axis electron holography. Nano Lett. 16, 3748-3753 (2016).

90. Taheri, M. L. et al. Current status and future directions for in situ transmission electron microscopy. Ultramicroscopy 170, 86-95 (2016).

91. Ihee, H. et al. Direct imaging of transient molecular structures with ultrafast diffraction. Science 291, 458-462 (2001).

92. Lysenko, S., Rúa, A., Vikhnin, V., Fernández, F. \& Liu, H. Insulator-to-metal phase transition and recovery processes in $\mathrm{VO}_{2}$ thin films after femtosecond laser excitation. Phys. Rev. B 76, 035104 (2007).

93. Picher, M., Mazzucco, S., Blankenship, S. \& Sharma, R. Vibrational and optical spectroscopies integrated with environmental transmission electron microscopy. Ultramicroscopy 150, 10-15 (2015).

94. Allen, F., Kim, E., Andresen, N., Grigoropoulos, C. \& Minor, A. In situ TEM Raman spectroscopy and laser-based materials modification. Ultramicroscopy 178, 33-37 (2017).

95. Zhu, Z. et al. In situ mass spectrometric determination of molecular structural evolution at the solid electrolyte interphase in lithium-ion batteries. Nano Lett. 15, 6170-6176 (2015).

96. Yedra, L., Eswara, S., Dowsett, D. \& Wirtz, T. In-situ isotopic analysis at nanoscale using parallel ion electron spectrometry: a powerful new paradigm for correlative microscopy. Sci. Rep. 6, 28705 (2016) 
97. Unocic, R. R. et al. Probing battery chemistry with liquid cell electron energy loss spectroscopy. Chem. Commun. 51, 16377-16380 (2015).

98. Hutzler, A., Branscheid, R., Jank, M. P. M., Frey, L. \& Spiecker, E. The 16th European Microscopy Congress 2016 (Instrumentation and Methods, Lyon, France).

99. Zaluzec, N. J., Burke, M. G., Haigh, S. J. \& Kulzick, M. A. X-ray energydispersive spectrometry during in situ liquid cell studies using an analytical electron microscope. Microsc. Microanal. 20, 323-329 (2014).

100. Yuk, J. M. et al. High-resolution EM of colloidal nanocrystal growth using graphene liquid cells. Science 336, 61-64 (2012).

101. Wang, C., Shokuhfar, T. \& Klie, R. F. Precise in situ modulation of local liquid chemistry via electron irradiation in nanoreactors based on graphene liquid cells. Adv. Mater. 28, 7716-7722 (2016).

102. Suo, L. et al. "Water-in-salt" electrolyte enables high-voltage aqueous lithiumion chemistries. Science 350, 938-943 (2015).

103. Liu, X. et al. In situ transmission electron microscopy of electrochemical lithiation, delithiation and deformation of individual graphene nanoribbons. Carbon N. Y. 50, 3836-3844 (2012).

104. Su, Q. et al. Visualizing the electrochemical reaction of $\mathrm{ZnO}$ nanoparticles with lithium by in situ TEM: two reaction modes are revealed. Nanotechnology 24, 255705 (2013).

105. Liang, W. et al. Nanovoid formation and annihilation in gallium nanodroplets under lithiation-delithiation cycling. Nano Lett. 13, 5212-5217 (2013).

106. Zhu, B. et al. Interfacial stabilizing effect of $\mathrm{ZnO}$ on $\mathrm{Si}$ anodes for lithium ion battery. Nano Energy 13, 620-625 (2015).

107. Luo, L. et al. Surface-coating regulated lithiation kinetics and degradation in silicon nanowires for lithium ion battery. ACS Nano 9, 5559-5566 (2015).

108. Krumeich, F., Waser, O. \& Pratsinis, S. E. Thermal annealing dynamics of carbon-coated $\mathrm{LiFePO}_{4}$ nanoparticles studied by in-situ analysis. J. Solid State Chem. 242, 96-102 (2016).

109. Liu, Y. et al. In situ transmission electron microscopy study of electrochemical sodiation and potassiation of carbon nanofibers. Nano Lett. 14, 3445-3452 (2014).

110. Wang, J., Liu, X., Mao, S. X. \& Huang, J. Microstructural evolution of tin nanoparticles during in situ sodium insertion and extraction. Nano Lett. 12, 5897-5902 (2012).

111. Sun, J. et al. A phosphorene-graphene hybrid material as a high-capacity anode for sodium-ion batteries. Nat. Nanotechnol. 10, 980-985 (2015). This paper develops a high-capacity anode based on phosphorene with its storaged mechaisms identified to be a combination of $\mathrm{Na}^{+}$intercalation and $\mathrm{Na}-\mathrm{P}$ alloying processes.

112. Nie, A. et al. Selective ionic transport pathways in phosphorene. Nano Lett. 16, 2240-2247 (2016).

113. Li, Z. et al. Coupling in situ TEM and ex situ analysis to understand heterogeneous sodiation of antimony. Nano Lett. 15, 6339-6348 (2015).
114. Lu, X. et al. Germanium as a sodium ion battery material: in situ TEM reveals fast sodiation kinetics with high capacity. Chem. Mater. 28, 1236-1242 (2016).

\section{Acknowledgements}

This work was supported by the US Department of Energy under Contract DE-AC0206CH11357 with the support provided by the Vehicle Technologies Office, Department of Energy (DOE) Office of Energy Efficiency and Renewable Energy (EERE) R.S.-Y. acknowledges the financial support from the National Science Foundation (Award No. CMMI-1619743). Partial funding for Y.Y. from Argonne National Laboratory under subcontract No. 4J-30361 is acknowledged. K.A. and J.L. acknowledge the finical support from the Center for Electrical Energy Storage, an Energy Frontier Research Center funded by the US Department of Energy, Office of Science, Office of Basic Energy Sciences. We thank Boao Song, Kun He and Dr. Anmin Nie from the University of Illinois at Chicago for their support in the figure design and manuscript discussion.

\section{Additional information}

Competing interests: The authors declare no competing financial interests.

Reprints and permission information is available online at http://npg.nature.com/ reprintsandpermissions/

How to cite this article: Yuan, Y. et al. Understanding materials challenges for rechargeable ion batteries with in situ transmission electron microscopy. Nat. Commun. 8, 15806 doi: $10.1038 /$ ncomms15806 (2017).

Publisher's note: Springer Nature remains neutral with regard to jurisdictional claims in published maps and institutional affiliations.

(c) (i) Open Access This article is licensed under a Creative Commons Attribution 4.0 International License, which permits use, sharing, adaptation, distribution and reproduction in any medium or format, as long as you give appropriate credit to the original author(s) and the source, provide a link to the Creative Commons license, and indicate if changes were made. The images or other third party material in this article are included in the article's Creative Commons license, unless indicated otherwise in a credit line to the material. If material is not included in the article's Creative Commons license and your intended use is not permitted by statutory regulation or exceeds the permitted use, you will need to obtain permission directly from the copyright holder. To view a copy of this license, visit http://creativecommons.org/ licenses/by/4.0/

C The Author(s) 2017 